\title{
SENTIDOS PRODUZIDOS EM CENA: EQUÍVOCOS E DESLOCAMENTOS NA PEÇA DEUS LHE PAGUE
}

\author{
AMANDA MARIA BICUDO DE SOUZA ${ }^{1}$
}

Programa de Pós-graduação em Ciências da Linguagem

Faculdade de Filosofia, Ciências e Letras Eugênio Pacelli - Universidade do Vale do Sapucaí - Av. Pref. Tuany Toledo, 470 - 37550-000 - Pouso Alegre - MG - Brasil

amandadysouza@ifsp.edu.br

\begin{abstract}
Resumo. Nessa pesquisa, temos como objetivo identificar as marcas discursivas que apontam para o movimento de resistência $e$ o funcionamento do absurdo na peça teatral Deus lhe pague, compreendendo aquele como uma forma de equívoco (GADET e PECCHEUX, 2004; PAYER, 2012). Tomaremos como norteadores os pressupostos teóricometodológicos da Análise de Discurso Francesa (AD). Escolhemos a AD como fundamentação teórico-metodológica de análise de uma peça teatral, devido à possibilidade de interpretação de sentidos que a perspectiva discursiva nos permite ao tomar como base o texto dramatúrgico. Tomaremos como corpus alguns recortes discursivos, de modo a vislumbrar o funcionamento do absurdo bem como identificar as marcas de resistência na peça Deus lhe pague. Pensamos, desse modo, poder contribuir para as reflexões acerca da leitura de textos dramatúrgicos no quadro teóricometodológico da análise de discurso.
\end{abstract}

Palavras-chave: texto dramatúrgico; análise discursiva; resistência; absurdo.

\begin{abstract}
In this research, we aim at identifying the discursive marks that point to the resistance movement and the operation of the absurd in Deus lhe pague play, understanding that as a form of misunderstanding (GADET and PECHEUX, 2004; PAYER, 2012. We base our analysis in the theoretical-methodological assumptions of French Discourse Analysis (FDA). We chose FDA as the theoretical-methodological basis for the analysis of a play, due to the possibility of interpretation of meanings that the discursive perspective allows us to take as a basis the dramaturgical text. We will take as corpus some discursive clippings, in order to glimpse the workings of the absurd as well as to identify the marks of resistance in Deus the pague play. We think, in this way, to be able to contribute to the reflections about the reading of dramaturgical texts in the theoreticalmethodological framework of discourse analysis.
\end{abstract}

Keywords: dramaturgical text; discursive analysis; resistance; absurd.

\footnotetext{
${ }^{1}$ Doutoranda em Ciências da Linguagem pela Universidade do Vale do Sapucaí - UNIVÁS. Docente no IFSP - campus Jacareí.
} 


\section{ABRINDO AS CORTINAS: O TEXTO DRAMATÚRGICO EM ANÁLISE DE DISCURSO}

O texto dramatúrgico é comumente compreendido como gênero dramático ou teatral, sendo parte de um dos três gêneros literários, ao lado do gênero lírico e épico. (BAKHTIN, 2003). Enquanto gênero literário, é compreendido como um tipo relativamente estável de enunciado que cumpre um propósito comunicativo e possui uma forma composicional.

De nossa parte, não desconsideramos as concepções supracitadas acerca do texto dramatúrgico, porém, de uma forma mais ampla, o tomamos como materialidade da poesia/língua, materialidade do discurso literário. Segundo Gadet e Pêcheux (2004), a poesia é inerente à língua, é propriedade dela, sendo somente nela possível. Nesse sentido, a língua é matéria-prima da poesia.

De acordo com Almeida (2016), a poesia é um mecanismo próprio da língua, que se define na ordem da constituição/formulação/circulação e, por isso, supõe o funcionamento da memória discursiva, pela repetição e, ao mesmo tempo, atualização de sentidos e formulações.

D’Olivo (2018), ao fazer a análise/leitura de cordéis, pontua que "o ritual da escrita e organização do/no cordel configura um espaço já estabelecido, já-dado, para o trabalho dos cordelistas com o significante". O mesmo é possível afirmar sobre o texto dramatúrgico. Há um ritual da língua e uma organização, que estão na ordem da formulação, que cerceiam o sujeito-dramaturgo e regulam seu modo de usar as palavras e produzir sentidos, ou seja, o dramaturgo "joga com o significante, dentro de uma estrutura já-dada, para organizar e estruturar a sua relação com o exterior" (D'OLIVO, 2018, p. 339). O modo como o texto dramatúrgico é organizado "estabelece uma relação intrínseca com a memória, a partir da circularidade na sociedade e na história" (PAYER, 2006 apud SALLES, 2012, p. 83).

Sendo a língua materialidade do discurso, e a poesia, propriedade da língua, situamos o texto dramatúrgico de Joracy Camargo como materialidade do discurso literário e o compreendemos no funcionamento da memória discursiva, considerando a historicidade que o constitui em seu processo de formulação/circulação e o modo como o sujeito-dramaturgo se inscreve e se constitui nessa materialidade linguística.

\section{SOBRE EQUÍVOCO, DESLOCAMENTO E RUPTURA}

$\mathrm{Na}$ Análise de Discurso (AD), tanto os sujeitos como a linguagem são compreendidos enquanto incompletos, inacabados. Ambos estão sempre se fazendo num contínuo movimento entre o simbólico e a história. Nesse contexto, a língua é compreendida "como um sistema sintático passível de jogo, de equívocos, sujeita a falha". (ORLANDI, 2003, p. 47). Segundo Orlandi, é o gesto de interpretação que torna possível a relação do sujeito com a língua, a história e os sentidos, "podendo assim tanto estabilizar como deslocar sentidos" (2003, p. 48). 
Orlandi afirma que o funcionamento da linguagem se dá na tensão entre paráfrase e polissemia, sendo a paráfrase da ordem da memória, do dizível, da estabilização e a polissemia da ordem do deslocamento, da ruptura nos processos de significação. Segundo a referida autora, a polissemia joga com o equívoco. (ORLANDI, 2003).

No que se refere à memória, Orlandi (2003) afirma que pelo viés da $\mathrm{AD}$, a memória é tratada como memória discursiva, interdiscurso, sendo este definido como algo que está na base do dizível, no plano da constituição, e que retorna sob a forma de préconstruído. Dessa forma, os sentidos são produzidos no jogo entre constituição (interdiscurso, memória) e formulação (intradiscurso, atualidade) e existem exclusivamente nas relações de metáfora, aqui compreendida enquanto transferência, ponto de articulação do equívoco, do irrealizado.

Ferreira (1994) afirma que o equívoco se manifesta e significa sob diferentes formas e encoberto sob diferentes marcas sintáticas. Segundo a referida autora (FERREIRA, 1994, p. 134), o modo como o equívoco se materializa "pode ser pelo viés da falta, do excesso, do repetido, do parecido, do absurdo, do non-sense". Seja qual for sua materialidade, o que há em todas elas é um processo de ruptura que afeta diretamente na produção de sentidos.

Segundo Ferreira (1994) de modo a abordar o fato linguístico do equívoco, o analista de linguagem precisa construir procedimentos para apreender o jogo de diferenças, de contradições, do absurdo que se instaura no/pelo discurso.

Tomando a língua em seu caráter de incompletude e não-fechamento, Ferreira afirma que as inter-relações que a língua estabelece são de ordens diferentes: gramatical, ideológica, social e cultural. Para a referida autora, "nos jogos com a língua esses diversos níveis podem ser acionados e, de alguma forma, violados, desencadeando, em consequência, o riso". (FERREIRA, 1994, p. 139). No caso do presente trabalho, tomamos o absurdo como fato linguístico do equívoco que se dá na ordem do ideológico e do social, instaurando um efeito de humor enquanto mecanismo de funcionamento que opera na base de violação de certos preceitos. (FERREIRA, 1994).

Ao compreender a relação que se estabelece no batimento entre paráfrase e polissemia, entre constituição e formulação, entre o simbólico e a história, bem como os efeitos metafóricos que se dão nesse entremeio, o analista de linguagem se propõe a compreender a relação que se dá entre o político e o linguístico ao constituírem os sujeitos e produzirem sentidos, "num espaço fortemente regido pela simbolização das relações de poder" (ORLANDI, 2003, p. 38).

\section{EM CENA: DISCURSO SOCIAL E RESISTÊNCIA}

Julgamos importante trazer para a discussão o modo como a $\mathrm{AD}$ compreende discurso social e resistência, porque o objeto discursivo de nossa pesquisa diz respeito a um dizer da arte, que toma como base um discurso social e produz sentidos de resistência, por meio do equívoco instaurado pela linguagem. 
Ferreira (1994, p. 7) afirma que, do equívoco surgiu a noção de resistência e que tal noção abarca três "diferentes ordens: a ordem da língua, do sujeito e do mundo". No que se refere à ordem da língua e do sujeito, a referida autora mostra que o trabalho do analista se dá num movimento de compreensão da polaridade da língua e do sujeito, ou seja, ora o sujeito domina a linguagem (na ilusão de um eu centralizador de sentidos e na transparência da linguagem - esquecimentos 1 e 2 (PÊCHEUX, 1988), ora ele é dominado por ela (assujeitado). Com relação à resistência do mundo, Ferreira (1994) diz que esta constitui-se na exterioridade e remete à relação da $\mathrm{AD}$ com a História, a sociedade e as relações de poder.

Orlandi (2007) explica que para compreender os mecanismos da linguagem de resistência é preciso fazer deslocamentos no modo como concebemos o discurso, ou seja, faz-se necessário compreendê-lo na complexidade que o constitui (linguísticahistórica-ideológica) e não apenas em sua posição enquanto lugar de reprodução. Há que se produzir um trabalho histórico de sentido que tome o discurso também enquanto lugar de resistência e transformação.

Sobre discurso social, Maingueneau (1984 apud Orlandi, 2007, p.111) postula que a prática discursiva é constituída por duas faces: a primeira é o grupo social, ou seja, o povo, os sujeitos; e a segunda é a textualidade que constitui esse povo: o discurso social. Nesse contexto, o autor (em nosso caso, o artista) é tomado como personagem do discurso social, cabendo-lhe a função e posição imaginárias de produtor de sentidos e origem do discurso.

Rancière (2005, p. 18 e 19) afirma que a "arte é uma forma de inscrição do sentido da comunidade e reflete estruturas ou movimentos sociais". Para o referido autor, a prática artística é uma forma de visibilidade deslocada, ou seja, assim como a política, a arte constrói "rearranjos materiais dos signos e das imagens, das relações entre o que se vê e o que se diz, entre o que se faz e o que se pode fazer". (RANCIÈRE, 2005, p. 59). Dessa forma, tomada enquanto discurso de resistência, a arte "produz uma espécie de reversão do discurso social, sem no entanto negá-lo" (ORLANDI, 2007, p. 113). Ao produzir deslocamentos, deslizamentos, falhas, equívocos, a prática artística funciona como uma prática política, cuja função é transformar as relações sociais sendo ambas - arte e política - ferramentas de reflexão (INDURSKY, 2015, p. 302).

\section{O ABSURDO COMO FORMA DE RESISTÊNCIA}

No texto dramatúrgico que tomamos como objeto discursivo destacamos o sujeito personagem principal - um mendigo - que antes de mendigar foi operário justo e honesto e trabalhou por muito tempo no projeto de um grande invento, cuja ideia foi roubada por seu patrão. Após esse episódio, o mendigo decide deixar a vida de operário e resolve mendigar e, mendigando, enriquece. Esse fato, especificamente, e o modo como se desenrola o enredo da peça, encontra-se na ordem do absurdo, soa estranho, desestrutura a ordem capitalista social, muda o rumo, o sentido da história, e ao desviar o sentido, produz um efeito cômico. No entanto, o efeito cômico produzido e os sentidos que dele derivam acontecem enquanto movimento de resistência, produzindo, como aponta Pêcheux (1990), um acontecimento histórico, pois rompe com o círculo da repetição. 
Pelo jogo discursivo que a linguagem da arte possibilita e com base em Gadet e Pêcheux (2004) é possível dizer que em Deus lhe pague o absurdo não se dá na ordem da lógica, mas supõe um desvio pela língua, sendo utilizado como ferramenta reflexiva e questionadora, na qual a questão política se revela na contradição, na diferença.

Compreendemos o absurdo corroborando com o dizer de Payer (2012, p. 35) que mostra seu funcionamento na narrativa como sendo algo excessivo na/da ordem discursiva. No entanto, embora excessivo (absurdo) produz um efeito de normalidade. O sujeito personagem da obra (o mendigo rico) entende a posição que ocupa (de ser mendigo e de ser rico) como sendo algo normal, possível a outras pessoas que tenham o desejo de se tornar como ele.

Desta forma, tomamos o absurdo como equívoco, uma forma de ruptura que produz deslocamentos de ordem ideológica e discursiva. Como afirma Payer (2012, p. 41), "trata-se da passagem da ruptura como horizonte do dizer ao deslocamento como possibilidade do dizer, por formulações que resultam do trabalho da memória discursiva junto às tensões do conflito".

Compreendido como texto político, o enredo deste objeto discursivo se despede "do sentido que reproduz o discurso da dominação" e deixa vir à tona o irrealizado, transgride fronteiras ao questionar uma ordem. (PÊCHEUX, 1999, p. 17).

O mendigo (sujeito personagem principal da obra) surge como porta-voz (PÊCHEUX, 1999, p. 17) - "ator visível e testemunha ocular do acontecimento" - pois ele dá visibilidade ao antes invisível, "se expõe ao olhar do poder que ele afronta, falando em nome daqueles que ele representa". Embora seja uma personagem fictícia, parte constituinte do discurso artístico, o mendigo é a representação do povo oprimido, do operário injustiçado. Suas palavras trazem a indignação de um grupo, verbalizam não-ditos e simbolizam outras tantas vozes. Seus dizeres apontam as mazelas do sistema capitalista para a própria burguesia que assistiu e assiste à peça. Como afirma Pêcheux (1999, p. 17) o porta-voz tem "dupla visibilidade: ele fala diante dos seus e parlamenta com o adversário".

Assim, nos recortes discursivos que apresentaremos mais adiante, buscaremos analisar o funcionamento do absurdo no texto dramatúrgico, as rupturas discursivas e os deslocamentos de sentido que acontecem durante a narrativa do sujeito personagem principal da obra.

\section{DEUS LHE PAGUE: CONDIÇÕES DE PRODUÇÃO}

Antes de iniciarmos a análise dos recortes discursivos, julgamos importante (e necessário) refletir acerca das condições de produção da peça teatral que tomamos como objeto discursivo.

De acordo com Orlandi (2003), as condições de produção se referem aos sujeitos, à situação e à memória, esta tomada como parte da produção do discurso. Segundo a referida autora (ORLANDI, 2017, p. 15) "como nascemos sempre num determinado 
contexto real e concreto, já estamos, somente por isso, comprometidos com ele, isto é, com o mundo no qual temos que viver". Dessa forma, pensar na noção de sujeito e situação é pensar em condições de produção do discurso. Trata-se de considerar o sujeito enquanto perpassado e constituído pela língua e pela ideologia, em sua formasujeito histórica, que resulta na sua ilusão como origem e na ilusão referencial (ORLANDI, 2017, p. 27). E pensar na situação enquanto interdiscurso, memória, historicidade, exterioridade, interpretação.

Considerando as condições de produção em sentido amplo tomamos primeiramente o discurso da arte dentro dessas condições e o compreendemos enquanto discurso de resistência (ORLANDI, 2007, p. 113), por meio do qual arte e política se entrelaçam. Segundo Rancière (2005, p. 59), tanto o enunciador político quanto o enunciador literário fazem efeito no real, pois "traçam mapas do visível, trajetórias entre o visível e o dizível, relações entre modos de ser, modos de fazer e modos de dizer". Porém, "as vias da subjetivação política não são as da identificação imaginária, mas as da desincorporação literária” (RANCIÈRE, 2005, p. 60 e 61).

Ainda refletindo acerca das condições de produção em sentido amplo, consideramos a historicidade constitutiva da peça Deus lhe pague, destacando o fato de que ela foi apresentada, pela primeira vez, em 1932. Nesse período, o país estava sob comando do Governo Provisório de Getúlio Vargas e passava por um momento de reestruturação econômica e política. A temática da peça gira em torno das questões do proletariado e faz uma crítica à estrutura social burguesa. Dessa forma, conforme dizer de Orlandi (2017) supracitado, Joracy Camargo, autor do texto dramatúrgico, mostra-se comprometido com o contexto real e concreto no qual está inserido, com suas condições materiais de existência. Ao abordar questões sociais em seu texto artístico, Joracy Camargo traz para a reflexão aspectos referentes à situação histórica em que vive e utiliza o discurso da arte para apontar as mazelas sociais, para dar voz (pela resistência que o discurso da arte possibilita) ao que estava silenciado.

Pensando as condições de produção em sentido estrito, posicionamos o sujeitoautor dentro dessas condições e acerca dele destacamos o fato de que ele nasceu em 1898 e morreu em 1973. Foi dramaturgo, teatrólogo, jornalista, cronista e professor, tornando-se membro da Academia Brasileira de Letras, em 1967. A respeito de Joracy Schafflor Camargo, trazemos alguns recortes que se encontram no prefácio de sua obra e foram escritos por Magalhães Júnior e Afrânio Coutinho. Ambos têm seus dizeres legitimados e ocuparam várias posições enunciativas em suas vidas, dentre elas a de membros da Academia Brasileira de Letras.

Como uma ponte entre essa geração e a atual, Joracy Camargo foi o primeiro a ter a percepção de que era necessário abrir caminhos novos e trazer para a cena o debate de problemas antes proibidos (MAGALHÃES JÚNIOR apud CAMARGO, 1980, p. 6).

No terreno dramático, creio não ser exagerado, e o êxito alcançado entre nós o confirma, dizendo que a maior realização brasileira até hoje é o teatro de Joracy Camargo. Com seu conjunto de peças já se pode falar em teatro no Brasil, não só quanto ao seu valor artístico mas, sobretudo quanto ao seu sentido social (AFRÂNIO COUTINHO apud CAMARGO, 1980, p. 7). 
Para ele, o teatro deve ser apenas o instrumento de um debate de teses, um bisturi de dissecação social e moral, um meio de análise, um veículo de ideias (AFRÂNIO COUTINHO apud CAMARGO, 1980, p. 8).

Pelos dizeres de Magalhães Júnior e Afrânio Coutinho é possível entender um pouco do modo como Joracy Camargo compreendia a arte e a sociedade.

Ainda tomando como reflexão o contexto imediato de produção da peça, destacamos o fato de que ela foi representada pela primeira vez em São Paulo, no Teatro Boa Vista, em 30 de dezembro de 1932, pela Compania Procópio Ferreira. Foi a primeira peça teatral brasileira encenada no exterior, tendo alcançado prestígio internacional e foi representada mais de catorze mil vezes no Brasil, além de traduzida para diversas línguas.

A peça Deus lhe pague é caracterizada como comédia e está dividida em três atos. Suas personagens são: Mendigo/Juca (personagem principal), Outro (que se trata de um outro mendigo com quem o personagem principal dialoga), Maria (personagem secundária - esposa de Juca), Senhor (personagem secundário - empresário, patrão de Juca), Nancy (personagem secundária - mulher atual do Mendigo/Juca), Péricles (personagem secundário - amante de Nancy). O enredo gira em torno da história de Juca, um operário muito inteligente que criou uma nova máquina e teve sua ideia roubada por seu patrão. Maria, sua esposa, foi iludida e entregou ao patrão de Juca todo o projeto do maquinário que ele havia inventado. A partir desse episódio, Maria enlouquece e Juca decide abandonar o trabalho, torna-se um mendigo e fica rico. Conhece Nancy e passa a morar com ela. No entanto, Nancy não sabe que ele é um mendigo e só descobre esse fato no final da peça. Nancy se envolve com Péricles, mas não consegue abandonar o Mendigo (Juca) porque é psicologicamente dependente dele. O Mendigo (Juca) narra sua história a um Outro mendigo que conhece e se dispõe a ensiná-lo a enriquecer.

A respeito da obra, Magalhães Júnior e Afrânio Coutinho afirmam:

O que dá a medida do êxito de uma peça teatral é a sua capacidade de resistência ao tempo (MAGALHÃES JÚNIOR apud CAMARGO, 1980, p. 5).

... chegou a estar proibida por algum tempo, como subversiva, só com tremendo esforço vindo a ser posteriormente liberada (MAGALHÃES JÚNIOR apud CAMARGO, 1980, p. 6).

Deus lhe pague, de seu lado, repercutiu como uma bomba e chegou a inquietar a polícia: era uma peça que 'pensava' e 'fazia pensar'; no fundo, ela aceitava a organização social tal como existia mas, pela primeira vez, permitia-se criticá-la (MAGALHÃES JÚNIOR apud CAMARGO, 1980, p. 6).

Uma peça de teatro é de efeitos muito mais profundos e largos do que mil tratados de moral social e econômica, centenas de discursos e conferências. A sátira imensa que é a obra de Joracy Camargo tem um alcance como propaganda de ideias contra a burguesia e a concepção capitalista da vida que dificilmente se poderá prever. Nela está caricaturada essa mesma burguesia que o aplaude e ri ruidosamente, talvez inconscientemente, talvez inadvertidamente, talvez 
rotineiramente, talvez para abafar as vozes da consciência, o imenso remorso e o medo horrível que the vão nalma (AFRÂNIO COUTINHO apud CAMARGO, 1980, p. 7).

Novamente, pelos dizeres de Magalhães Júnior e Afrânio Coutinho é possível perceber o texto dramatúrgico de Joracy Camargo funcionando como instrumento de resistência, como mecanismo de crítica social, como espaço político de produção de sentidos. Nosso objetivo, nessa pesquisa, é mostrar, por meio dos recortes discursivos, como essa crítica social é produzida e quais deslocamentos derivam desse processo discursivo.

\section{ANÁLISE DOS RECORTES DISCURSIVOS}

Conforme citamos anteriormente, a peça Deus lhe pague está dividida em três atos. No primeiro ato, Juca (o mendigo rico) está na porta de uma igreja esmolando e nesse entremeio chega um outro mendigo. Os dois começam a conversar e o outro mendigo descobre que Juca é rico e que enriqueceu mendigando. Do primeiro ato, trazemos os seguintes recortes discursivos $(\mathrm{RD})$ :

RD1: Outro - Ainda não fiz nada hoje, velhinho. Tenho cigarros. Aceita um? (p. 15)

RD 2: Mendigo - Muito obrigado. Não fumo cigarros ordinários. Quer um charuto? É Havana! Tenho muitos! Custam $10 \$ 000$ cada um. (p. 15)

RD 3: Outro - Aceito, porque nunca tive jeito para roubar... (p. 15)

RD 4: Mendigo - Foram comprados. Ainda não sou ladrão... (p. 15)

RD 5: Outro-Desculpe. É que... (p. 15)

RD 6: Mendigo - Não é preciso pedir desculpas. Não sou ladrão, mas podia sê-lo. É um direito que me assiste. (p. 15)

Desse primeiro recorte, destacamos a fala do mendigo (RD2: Muito obrigado. Não fumo cigarros ordinários. Quer um charuto? É Havana! Tenho muitos! Custam $10 \$ 000$ cada um.) e identificamos nela o funcionamento do absurdo, ou seja, o equívoco produzido na/pela linguagem. Conforme fora supracitado, embora excessivo (absurdo), o dizer do mendigo produz um efeito de normalidade (PAYER, 2012), como se comprar um charuto Havana fosse algo comum/normal entre os mendigos. Há um deslocamento de sentidos que produz um efeito cômico e aponta para um movimento de resistência.

No RD6 (Não é preciso pedir desculpas. Não sou ladrão, mas podia sê-lo. É um direito que me assiste.) identificamos novamente o funcionamento do absurdo na afirmação do mendigo a respeito de seu direito de se tornar um ladrão. Ao enfatizar que esse é um direito que o assiste, o mendigo legitima sua afirmação, filiando seu dizer a formações discursivas que trazem à tona a memória do dizer jurídico, do Direito e remete à legislação, à constituição brasileira, aos direitos fundamentais do cidadão. No entanto, é o efeito de ironia produzido pela/na linguagem e as condições de produção em sentido amplo - a linguagem da arte - que possibilitam o deslocamento de sentidos, um desvio pela língua, o absurdo, que não se dá na ordem da lógica, conforme Gadet e Pêcheux (2004). 
A respeito do discurso da arte, pelo viés discursivo - pela AD - nós o compreendemos como espaço de possibilidades de dizeres, prática simbólica que coloca em funcionamento e dá visibilidade a discursos silenciados (MASSMANN, 2018, p. 44). Ancorados nas pesquisas de Massmann (2018) e Indursky (2015), tomamos a arte como prática política, cuja função é transformar as relações sociais, seja por meio da manutenção da ideologia dominante, seja como lugar de resistência "do sujeito, dos sentidos e da sociedade" (MASSMANN, 2018, p. 45).

Sendo o discurso da arte prática simbólica e política que funciona como espaço de visibilidade de dizeres silenciados, tomamos o discurso literário - e, aqui, especificamente, o texto dramatúrgico - como uma de suas materialidades.

Sobre o discurso literário, Fragoso (2014) compreende a literatura como uma prática discursiva cuja forma material é histórica, o que significa dizer que ela possui marcas e propriedades que são constituídas historicamente, na relação entre língua e exterioridade. Cabe ao analista de discurso descrever seu funcionamento, explicitando suas regularidades, de modo a melhor compreender a constituição, a formulação e a circulação dos sentidos. Segundo Fragoso (2014, p. 79), há um imaginário social que é sustentado pelo discurso literário e cujas representações "se apresentam como sendo naturais, apagando-se o trabalho social, ideológico e político produzido por este discurso". Além disso, produz no sujeito-autor, como efeito de evidência, a ilusão de que ele é causa e origem do que diz. Dessa forma, o que a literatura interpreta artisticamente, a $\mathrm{AD}$ toma como dispositivo ideológico em funcionamento no discurso literário.

Ainda do primeiro ato, destacamos outros recortes discursivos (RD):

RD7: Mendigo - Antigamente, tudo era de todos. Ninguém era dono da terra e a água não pertencia a ninguém. Hoje, cada pedaço de terra tem um dono e cada nascente de água pertence a alguém. Quem foi que deu? (p. 16)

RD8: Outro - Eu não fui... (p. 16)

RD9: Mendigo - Não foi ninguém. Os espertalhões, no princípio do mundo, apropriaram-se das coisas e inventaram a Justiça e a Polícia... (p. 16)

Dos recortes supracitados, destacamos o RD9 (Não foi ninguém. Os espertalhões, no princípio do mundo, apropriaram-se das coisas e inventaram a Justiça e a Polícia...) como um dizer que vai ao encontro do que postulamos anteriormente a respeito da posição do mendigo (Juca) enquanto porta-voz, representação do povo oprimido. Suas palavras trazem a indignação de um grupo, verbalizam não-ditos e simbolizam outras vozes. Seu dizer mostra a prática artística funcionando como prática política (INDURSKY, 2015).

RD10: Outro - Ora!... Quem é que precisa de um mendigo? (p. 17) RD11: Mendigo - Todos! Eles precisam muito mais de nós, do que nós deles. O mendigo é, neste momento, uma necessidade social. Quando eles dizem: "Quem dá aos pobres, empresta a Deus", confessam que não dão aos pobres, mas emprestam a Deus... Não há generosidade na esmola, há interesse (p. 17) 


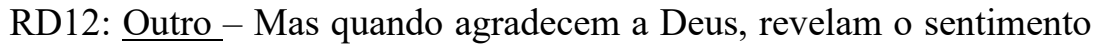
de gratidão. (p. 17)

RD13: Mendigo - Não há gratidão. Só agradece a Deus quem tem medo de perder a felicidade. Quem dá esmola pensa que está comprando a felicidade, e os mendigos, para eles, são os únicos vendedores desse bem supremo. (p. 17)

RD14: Outro - O senhor é contra esmola? (p. 17)

RD15: Mendigo - Sou a meu favor e contra os outros. A sociedade exige que eu peça. Eu peço. E foi pedindo que me vinguei dela. (p. 17) RD16: Outro - Como assim?! (p. 17)

RD17: Mendigo - Porque, obrigado a pedir, fui obrigado a enriquecer. (p. 17)

RD18: Outro - Há de me explicar como foi obrigado a ficar rico. (p. 17)

RD19: Mendigo - A sociedade é muito defeituosa, meu velho. Pela lógica, o mendigo deveria ser sempre pobre. Pelo menos, enquanto fosse mendigo. Entretanto, pobres, realmente pobres, são os ricos. Pobres de espírito, pobres de tranquilidade, de fraternidade, e, às vezes, até de dinheiro! (p. 17)

RD20: Outro - O senhor nasceu mendigo! (p. 20)

RD21: Mendigo - Não. Nasci trabalhador! Lutei muito pela vida! Luta desigual! Eu era um pobre operário, com a cabeça cheia de sonhos e com os braços em constante movimento. Cheguei às portas da fortuna e não pude entrar, porque me bateram com as portas na cara! (p. 20)

Nos recortes destacados acima, identificamos novamente a materialização do equívoco pelo viés do absurdo, um processo de ruptura que afeta na produção de sentidos, conforme mencionado por Ferreira (1994). Nos dizeres de RD11 (O mendigo é, neste momento, uma necessidade social), RD13 (Quem dá esmola pensa que está comprando a felicidade, e os mendigos, para eles, são os únicos vendedores desse bem supremo), RD15 (A sociedade exige que eu peça. Eu peço. E foi pedindo que me vinguei dela) e RD17 (Porque, obrigado a pedir, fui obrigado a enriquecer) o absurdo se dá na ordem do ideológico e do social, instaurando um efeito de humor enquanto mecanismo de funcionamento que opera na base de violação de certos preceitos. (FERREIRA, 1994).

Nos RD19 (A sociedade é muito defeituosa, meu velho. Pela lógica, o mendigo deveria ser sempre pobre. Pelo menos, enquanto fosse mendigo. Entretanto, pobres, realmente pobres, são os ricos. Pobres de espírito, pobres de tranquilidade, de fraternidade, e, às vezes, até de dinheiro!) e RD21 (Não. Nasci trabalhador! Lutei muito pela vida! Luta desigual! Eu era um pobre operário, com a cabeça cheia de sonhos e com os braços em constante movimento. Cheguei às portas da fortuna e não pude entrar, porque me bateram com as portas na cara!) temos, mais uma vez, o dizer do mendigo representando o dizer da classe trabalhadora, oprimida. Em sua voz ecoam outras vozes. Seus dizeres apontam as mazelas do sistema capitalista e dos tipos de relações sociais e subjetividades que a forma de nossa existência produz (DARDOT e LAVAL, 2016). O dizer do mendigo surge como uma forma de ruptura que produz deslocamentos de ordem ideológica e discursiva. Como afirma Payer (2012, p. 41), "trata-se da passagem da ruptura como horizonte do dizer (não-dito, proibido, 
silenciado) ao deslocamento como possibilidade do dizer, por formulações que resultam do trabalho da memória discursiva junto às tensões do conflito.

No que se refere ao segundo ato, após narrar para o mendigo sua história de vida, o que o levou a deixar de ser trabalhador e tornar-se mendigo e o modo como enriqueceu, Juca continua conversando com ele acerca de outros aspectos da sociedade que o incomodam, ou melhor, acerca do modo como compreende a vida em sociedade. Desse ato, retiramos os recortes:

RD22: Mendigo - Não agradeça. O que exijo é absoluta obediência para que eu não sofra a mesma desilusão que tive com meu último protegido. (p. 28)

RD23: $\underline{\text { Outro }}$ - Foi ingrato? (p. 28)

RD24: Mendigo - Não. Foi idiota. Fiquei penalizado com a sua desobediência. Era um rapaz com todas as qualidades indispensáveis a um mendigo, e todas as condições físicas: magro... rosto encovado... olheiras... cabelos louros e finos. Era impressionante! Dava a impressão de filho de gente nobre arruinada. Belo exemplar de mendigo!... (p. 28)

RD25: $\underline{\text { Outro }}$ - E afinal? (p. 28)

RD26: Mendigo - Abandonou a carreira, miseravelmente! Ofereceram-lhe um emprego público e o desgraçado aceitou! (p. 28)

RD27: Outro - Naturalmente! É como se tivesse tirado a sorte grande! (p. 28)

RD28: Mendigo - Qual! Hoje é um infeliz: ganha um conto e duzentos por mês! O emprego, com ordenado fixo, é o ideal do homem vencido pela vida. Os cargos públicos inutilizam os homens. E, se um dia são dispensados, desorientam-se; têm pavor da vida, sem a proteção do Estado. (p. 28 e 29)

Nestes recortes discursivos, vemos novamente o funcionamento do absurdo enquanto acontecimento linguístico que se dá na ordem do ideológico e do social, produzindo deslocamentos de sentidos. No RD24 (Era um rapaz com todas as qualidades indispensáveis a um mendigo, e todas as condições físicas: magro... rosto encovado... olheiras... cabelos louros e finos. Era impressionante! Dava a impressão de filho de gente nobre arruinada. Belo exemplar de mendigo!), Juca descreve um modelo ideal de mendigo, conforme os padrões da sociedade. Um dizer que produz uma ruptura no processo de produção de sentidos - já que é pouco provável que na sociedade em que vivemos se conceba um modelo de mendigo a ser seguido - e que abre lugar ao equívoco pelo trabalho do léxico (dos grupos nominais) e dos sentidos possíveis que esse trabalho permite, produzindo um efeito de humor, de ironia, num movimento de resistência.

Identificamos também, no RD28 (Qual! Hoje é um infeliz: ganha um conto e duzentos por mês! O emprego, com ordenado fixo, é o ideal do homem vencido pela vida. Os cargos públicos inutilizam os homens. E, se um dia são dispensados, desorientam-se; têm pavor da vida, sem a proteção do Estado.), o discurso da arte funcionando como espaço de resistência, prática política. Ao trazer para o diálogo a estabilidade dos empregos públicos e as implicações da posição 'funcionário público', Juca (personagem fictício que simboliza a voz do autor da obra - Joracy Camargo) denuncia o modo como os sujeitos se inscrevem nesta formação discursiva e atuam 
nesta posição-sujeito e deixa transparecer a sua própria formação discursiva que questiona o sistema capitalista no modo como ele é organizado e vivenciado. Temos, então, o discurso da arte funcionando como reflexo de "estruturas ou movimentos sociais" (RANCIÈRE, 2005, p. 59), espaço de possibilidade de dizeres, prática de resistência materializada no texto dramatúrgico, que 'produz uma espécie de reversão do discurso social, sem no entanto negá-lo" (ORLANDI, 2007, p. 113).

Ainda do segundo ato, retiramos os recortes abaixo:

RD29: Mendigo - Bravos! Que bela inteligência! - Menandro, poeta grego do IV século antes de Cristo, também disse isso! (p. 29)

RD30: Outro - O senhor sabe essas coisas? (p. 29)

RD31: Mendigo - E tantas outras! Quando não estou esmolando, estou lendo. (p. 29)

No RD31 (E tantas outras! Quando não estou esmolando, estou lendo.), temos uma afirmação do mendigo que produz um deslocamento de sentidos e um efeito cômico; a materialização do equívoco que se dá na ordem do social e do ideológico e que, novamente pelo viés do absurdo (excessivo), produz um efeito de normalidade, como se o hábito de leitura fosse um hábito regular entre os mendigos.

RD29: Mendigo - Não há mais filósofos, meu caro. A sabedoria humana está muito espalhada. Hoje, todos sabem tudo. Não há mais segredos, nem mistérios. O último dos ignorantes julga-se capaz de salvar a humanidade. Ninguém mais aprende. Todos ensinam. (p. 36)

RD30: Péricles - Se não me engano, pela sua maneira de falar, o senhor é comunista! (p. 37)

RD31: Mendigo - Psiu! Silêncio! Comunismo é palavra que quer entrar para o dicionário, com escalas pela Polícia... (p. 37)

Nos recortes acima temos um diálogo entre Juca (o mendigo rico) e Péricles (amante de sua esposa). Não vamos aqui nos ater ao enredo da obra, nem tampouco opinar acerca do modo como ele se desenrola. Interessa-nos mostrar recortes linguísticos por meio dos quais o equívoco se materializa. No que diz respeito aos recortes selecionados, destacamos o RD29 (A sabedoria humana está muito espalhada. Hoje, todos sabem tudo. Não há mais segredos, nem mistérios. O último dos ignorantes julga-se capaz de salvar a humanidade. Ninguém mais aprende. Todos ensinam.) e identificamos nele um discurso de natureza complexa, cuja constituição linguísticahistórica-ideológica (ORLANDI, 2007) aponta para algo que se mantém. Um discurso produzido em 1932 que se atualiza em 2018; um equívoco que se materializa por meio da repetição, mas que produz outros sentidos ou perpetua o mesmo em outras condições de produção, deixando transparecer as mazelas sociais e subjetivas que constituem a sociedade e a nós mesmos.

Pelo dizer do mendigo, no RD31 (Psiu! Silêncio! Comunismo é palavra que quer entrar para o dicionário, com escalas pela Polícia...), é possível identificar o modo como uma única palavra - nesse caso, comunismo - significa de tal forma que enunciá-la pode acarretar consequências, remeter a sentidos não autorizados, contextos proibidos. Ao dizer que o termo 'quer entrar para o dicionário, com escalas pela Polícia', o mendigo aponta para algo que é da ordem da censura, para um dizer 
silenciado e enfatiza essa proibição do léxico pelo uso da interjeição 'Psiu! Silêncio'. Não se trata, aqui, de um equívoco, mas de um funcionamento discursivo que aponta para os sentidos que uma determinada palavra produz e o modo como esses sentidos situam o termo em determinadas condições de produção ou de enunciação, estando seu uso autorizado ou não conforme as 'leis' que norteiam a sociedade.

No terceiro e último ato identificamos, ainda, outros recortes discursivos que funcionam como discursos de resistência, questionando as condições de existência humana.

RD32: Mendigo - O homem é que é inimigo do próprio homem. Inimigo de si mesmo. $\mathrm{O}$ inventor da guilhotina foi guilhotinado... (p. 43)

RD33: Mendigo - Todas as religiões são perfeitas. Os homens é que são imperfeitos. Ninguém cumpre o que Deus determinou pela palavra do Messias. Mas como o dinheiro resolve tudo, compram o perdão de Deus por nosso intermédio. (p. 45)

RD34: Mendigo - Quem não passa fome e tem roupinha melhor para vestir, finge que é rico. A humanidade se compõe de miseráveis, falsos ricos e ricos falsos. A pior classe é a dos falsos ricos. (p. 45)

Nos RD32, RD33 e RD34, os dizeres do mendigo mostram o homem, o ser humano, como sendo imperfeito. É certo que a AD compreende o sujeito como um ser cindido, clivado, descentrado, incompleto, mas não é dessa incompletude que se trata o discurso do mendigo. Ao apontar para a imperfeição humana, ele a relaciona ao dinheiro, às questões materiais que moldam o sujeito capitalista e fazem com que ele se torne inimigo de si próprio. Há, aqui, o funcionamento do discurso da arte - do texto dramatúrgico - como ferramenta de reflexão (INDURSKY, 2015), como lugar de resistência e transformação (ORLANDI, 2007).

\section{FECHANDO AS CORTINAS: ALGUMAS CONSIDERAÇÕES FINAIS}

Em nosso percurso de análise estabelecemos como principal objetivo mostrar o funcionamento do equívoco no discurso dramatúrgico.

Por meio dos recortes que selecionamos, buscamos mostrar as marcas discursivas que apontam para um movimento de resistência que se dá no/pelo discurso e que traz à tona o não-dito, o silenciado, o proibido.

Corroboramos com o dizer de Massmann (2018, p. 44) a respeito da arte enquanto simbólico que dá visibilidade e coloca em funcionamento discursos silenciados. Como aponta a referida autora, "a arte sempre se constitui politicamente: seja como uma forma de manutenção da ideologia dominante, seja como um espaço de resistência do sujeito, dos sentidos e da sociedade" (MASSMANN, 2018, p. 45).

Podemos afirmar, no que se refere ao nosso objeto de análise - a obra Deus lhe pague - que o discurso literário funciona como espaço de resistência, como mecanismo de reflexão, de transformação. 
Dessa forma, compreender o texto dramatúrgico, ancorados em uma perspectiva discursiva, nos permitiu identificar os deslocamentos, de ordem ideológica e discursiva, que são produzidos por meio do equívoco, da ruptura, do absurdo.

Conforme apontamos na introdução desta pesquisa, ao tomar nosso objeto de análise na e pela intepretação discursiva (MASSMANN, 2018), buscamos propor um olhar outro sobre este objeto, uma compreensão que torne possível vislumbrar aquilo que resiste, o equívoco constitutivo da linguagem, a língua produzindo sentidos em condições de produção amplas e restritas.

Certamente, a análise deste objeto não se encerra aqui. Fecham-se imaginariamente as cortinas, mas não as leituras. Há outros sentidos que o texto dramatúrgico produz e que podem ser objeto de análises futuras. Há outras rupturas, outros deslocamentos...

\section{REFERÊNCIAS}

ALMEIDA, Eliana de. Na relação língua/poesia: as versões dos eubrasis e sujeitos nacionais. FRAGMENTUM [ISSN 2179-2194 (online); 1519-9894 (impresso) ], Programa de Pós-Graduação em Letras, Universidade Federal de Santa Maria (UFSM), Santa Maria (RS), n. 47, p.131-140, jan. - jul. 2016. Disponível em: https://periodicos.ufsm.br/fragmentum/issue/view/1014 Acesso em: 02/01/2019

BAKHTIN, Mikhail. Estética da criação verbal. $4^{\text {a }}$ ed. São Paulo: Martins Fontes, 2003.

CAMARGO, Joracy. Deus lhe pague. Coleção Prestígio: Ediouro, 1980.

DARDOT, Pierre e LAVAL, Christian. A nova razão do mundo: ensaio sobre a sociedade neoliberal. São Paulo: Boitempo, 2016.

D’OLIVO, Fernanda Moraes. Entre rimas e métricas: no jogo poético da materialidade significante do cordel. ENTREMEIOS [Revista de Estudos do Discurso, ISSN 21793514, on-line, www.entremeios.inf.br], Seção Temática [Discurso, arte e literatura Parte I], Programa de Pós-Graduação em Ciências da Linguagem (PPGCL), Universidade do Vale do Sapucaí (UNIVÁS), Pouso Alegre (MG), vol. 16, p. 327-342, jan.

jun.

2018.

DOI:http://dx.doi.org/10.20337/ISSN21793514revistaENTREMEIOSvol16pagina327a3 42.

FERREIRA, Maria Cristina Leandro. A resistência da língua nos limites da sintaxe e do discurso: da ambiguidade ao equívoco. Tese (Tese em Ciências da Linguagem). ÚNICAMP: Campinas, 1994. p.134 - 162 Disponível em: www.lume.ufrgs.br/bitstream/handle/10183/165468/000058526.pdf Acesso em: $03 / 05 / 2018$

FRAGOSO, Élcio Aloisio. Há separação entre língua e discurso? IGARAPÉ [Revista de Estudos de Literatura, Cultura e Alteridade], Porto Velho (RO), v.4, n.1, p.69-85, set. - dez. 2014.

GADET, Françoise; PÊCHEUX, Michel. Enigma, witz e joke. In: A língua inatingível: o discurso na história da linguística. $1^{\mathrm{a}}$ ed. Campinas: Pontes, 2004.

INDURSKY, Freda. Da produção à criação da obra de arte como gesto político. In: INDURSKY, Freda; FERREIRA, Maria Cristina Leandro; MITTMANN, Solange 
(orgs.) Análise do discurso: dos fundamentos aos desdobramentos - 30 anos de Michel Pêcheux. Campinas: Mercado de Letras: 2015. p. 289-303.

MASSMANN, Débora. O político na/da arte: instituições, discursos e resistências. In: ORLANDI, Eni Puccinelli; MASSMANN, Débora; DOMINGUES, Andrea Silva (orgs.) Linguagem, instituições e práticas sociais. Campinas: Editora UNIVÁS, 2018. p. 41-54

ORLANDI, Eni Puccinelli. Análise de discurso: princípios e procedimentos. $5^{\mathrm{a}}$ ed. Campinas: Pontes, 2003.

ORLANDI, Eni Puccinelli. As formas do silêncio: no movimento dos sentidos. $6^{\mathrm{a}}$ ed. Campinas: Editora da UNICAMP, 2007, p. 93-132

ORLANDI, Eni Puccinelli. Eu, tu, ele: discurso e real da história. $1^{\text {a }}$ ed. Campinas: Pontes, 2017.

PAYER, Maria Onice. A leitura em Abril Despedaçado: equívoco, deslocamento, acontecimento. In: CARROZZA, Guilherme; SANTOS, Mirian dos; SILVA, Telma Domingues da (orgs.) Sujeito, Sociedade, Sentidos. Campinas: Editora RG, 2012. p. $29-44$.

PÊCHEUX, Michel. Delimitações, inversões, deslocamentos. CADERNOS DE ESTUDOS LINGUÍSTICOS, $\mathrm{n}^{\circ} 19$. IEL/UNICAMP, 1999. Disponível em: https://periodicos.sbu.unicamp.br/ojs/index.php/cel/article/view/8636823/4544Acesso em 26/6/2018

PÊCHEUX, Michel. Discurso e ideologia(s). In: Semântica e discurso: uma crítica à afirmação do óbvio. Trad. Bras. Campinas: Ed. da Unicamp, 1988. p. 139-185

RANCIERE, Jacques. A partilha do sensível: estética e política. São Paulo: EXO Experimental, 2005.

SALLES, Atilio Catosso. Jornal e poesia: o Alencar espelhado no discurso da língua. RUA [online]. 2012, no. 18. Volume 1 - ISSN 1413-2109 Consultada no Portal Labeurb - Revista do Laboratório de Estudos Urbanos do Núcleo de Desenvolvimento da Criatividade http://www.labeurb.unicamp.br/rua/

\footnotetext{
$* * *$

Artigo recebido em: abr. de 2020.

Aprovado e revisado em: jun. de 2020.

Publicado em: julho de 2020.

Para citar este texto:

SOUZA, Amanda Maria Bicudo de. Sentidos Produzidos em Cena: equívocos e deslocamentos na peça Deus lhe pague. Entremeios [Revista de Estudos do Discurso, ISSN 2179-3514, online, www.entremeios.inf.br], Seção Estudos, Programa de Pós-Graduação em Ciências da Linguagem (PPGCL), Universidade do Vale do Sapucaí (UNIVÁS), Pouso Alegre (MG), vol. 21, p. 228-242, jan. - jun. 2020.

DOI: http://dx.doi.org/10.20337/ISSN2179-3514revistaENTREMEIOSvol21pagina228a242
} 